\title{
Different approaches for paraquat quantification in waters
}

\author{
Mónica S. F. Santos ${ }^{a}$, Luis M. Madeira ${ }^{a}$ and Arminda Alves ${ }^{a,{ }^{*}}$ \\ ${ }^{a}$ LEPABE - Laboratory for Process, Environmental, Biotechnology and Energy Engineering, \\ Faculty of Engineering, University of Porto, R. Dr. Roberto Frias, s/n, 4200-465 Porto, \\ Portugal
}

\begin{abstract}
Three analytical methodologies for paraquat (PQ) identification and quantification in waters were developed and validated in response to different scenarios: a direct injection-liquid chromatography-diode array detector (DI-LC-DAD) method for emergency situations, as occurs when there is a suspicion of contamination of drinking water networks; a solid phase extraction-liquid chromatography-diode array detector (SPE-LCDAD) method to control the drinking water quality and a direct injection-liquid chromatography-mass spectrometry (DI-LC-MS) method for confirmation purposes and identification of $P Q$ degradation by-products. Limits of detection of $10 \mu \mathrm{g} / \mathrm{L}, 0.04 \mu \mathrm{g} / \mathrm{L}$ and $20 \mu \mathrm{g} / \mathrm{L}$ PQ were reached for DI-LC-DAD, SPE-LC-DAD and DI-LC-MS methods, respectively. The PQ analytical response of DI-LC-DAD method was tested in different types of water and in the presence of other species (Fe(II) $\mathrm{H}_{2} \mathrm{O}_{2}$ and $\mathrm{Na}_{2} \mathrm{SO}_{3}$ ) or compounds resulting from the contact of the water with deposits and Pseudomonas fluorescens cells that exist in drinking water networks. Additionally, the method response
\end{abstract}

\footnotetext{
* Corresponding author. Tel.: +351-225081883; Fax: +351-225081449; E-mail: aalves@fe.up.pt
} 
was assessed when Gramoxone was used as PQ source instead of the analytical standard. Global uncertainties below 6, 11 and 13\% were found for DI-LC-MS, SPE-LC-DAD and DILC-DAD, respectively, for the most part of the calibration ranges. All methods proved to be precise, accurate and suitable for the purpose that they were designed.

Keywords: Paraquat; liquid chromatography with diode array detector; liquid chromatography-mass spectrometry; solid phase extraction; drinking water distribution systems; contamination

\section{Introduction}

Paraquat is a cationic compound extremely soluble in water and non-volatile, which has been widely used as herbicide around the world (nearly 90 countries). Its popularity is related to its quick and non-selective action to kill green plant tissue upon contact. Some studies proved that paraquat is one of the few herbicides capable of controlling the growth of weeds that became resistant as a result of over-use of non-selective glyphosate herbicides ${ }^{[1,2]}$. This bipyridylium herbicide is frequently reported as non-biodegradable and highly persistent, which contributes for its long residence time in the environment, and as a highly toxic substance ${ }^{[3-5]}$. The uncontrolled and abusive use of paraquat has generated a great concern related to the risk that it may represents to humans, animals and the environment ${ }^{[6]}$. Although, in some cases, this toxic weed killer is inactivated by irreversible adsorption on clays, which are the main components of the mineral fraction of soils, it has been detected in waters. Watercourse contamination may result from a vertical transport through the soil profile promoted by the dissolved colloids such as dissolved organic matter and dispersed colloidal clay ${ }^{[7]}$. Fernández et al. analyzed water 
samples from irrigation channels, rivers and lagoons taken from three different marsh areas of the Valencian community (Spain) and a paraquat concentration of $3.95 \mu \mathrm{g} / \mathrm{L}$ was detected $^{[8]}$. More recently (2006), paraquat concentrations between 1.5 and $18.9 \mu \mathrm{g} / \mathrm{L}$ and 9.3 and $87.0 \mu \mathrm{g} / \mathrm{L}$ were found in ground and surface water of Thailand, respectively ${ }^{[9]}$. Even at very low doses, this herbicide can pass some treatment steps and reach the water distribution systems, posing a threat to human health. Beyond the natural occurrence of paraquat in drinking water due to its large usage in some countries, its presence may be the result of a deliberate or accidental contamination ${ }^{[10,11]}$, which is the main focus of this work ${ }^{[12]}$. In those circumstances, the paraquat concentration in water could be very high, partially due to its high solubility in water, and different case scenarios should be considered on the development of the analytical methodologies. In particular, it is of crucial importance to have a simple and expedite method to quantify high PQ concentrations with good accuracy and precision, in a short time and using classical equipment, in order to be possible to make the analysis everywhere. Here, a simple DI-LC-DAD is proposed for emergency situations. On the other hand, a more sensitive methodology is also required, such as SPE-LC-DAD, to ensure that PQ levels in drinking water are below the limit recommended by European Union (maximum of 0.1 $\mu \mathrm{g} / \mathrm{L}$ for individual pesticide). Since the treatment of contaminated waters and their disposal are other important issues in case of a deliberate (or accidental) contamination event, it is also necessary to guarantee an unequivocal identification of paraquat and its degradation by-products in water. Fenton's reaction is an advanced oxidation process which uses $\mathrm{H}_{2} \mathrm{O}_{2}$ and $\mathrm{Fe}^{2+}$ as oxidant and catalyst, respectively, to degrade the organic matter. This degradation process was implemented for the degradation of $P Q$ in waters ${ }^{[13]}$. Although acceptable mineralization degrees were reported, a DI-LC-MS 
method is recommended for confirmation purposes and for identification of some degradation by-products formed during the Fenton's process.

Methods for PQ quantification in waters are already available in the literature and they are similar to the ones proposed here. However, it is important to emphasize that none of those studies considered the method validation applied to such different samples: in the presence of deposits, cells, and different types of water, which may represent realistic scenarios in drinking water networks. The analytical response of DI-LC-DAD was also analysed in the presence of Fenton's species which, to the author knowledge, was never investigated before. Additionally, a complete set of validation parameters, including the calculation of the global uncertainty associated to the results in the range of quantification, is presented for all developed methods.

\section{Experimental Section}

\subsection{Standard solutions and samples}

Paraquat dichloride (PQ) PESTANAL analytical standard (Fluka) was purchased from Sigma-Aldrich (St. Louis, USA). Gramoxone (GMX) with 25.6 wt. \% of PQ was kindly supplied by Syngenta Crop Protection, Lda. Heptafluorobutyric acid (HFBA) from SigmaAldrich (St. Louis, USA), acetonitrile (HPLC grade) from VWR BDH Prolabo (Fontenay-sousBois, France) and methanol (Lichrosolv ${ }^{\oplus}$ hypergrade for liquid chromatography) and water (Lichrosolv ${ }^{\circledR}$ for chromatography) from Merck (Darmstadt, Germany) were used for analysis.

Hydrogen peroxide solution $\left(\mathrm{H}_{2} \mathrm{O}_{2}, 30 \% \mathrm{v} / \mathrm{v}\right)$, iron (II) sulfate heptahydrate $\left(\mathrm{FeSO}_{4}, 99.5 \%\right)$ and anhydrous sodium sulfite $\left(\mathrm{Na}_{2} \mathrm{SO}_{3}, 96 \%\right)$ were purchased from Merck (Darmstadt, Germany) and used in interference tests. 
Ammonium chloride $\left(\mathrm{NH}_{4} \mathrm{Cl}, 99.9 \%\right)$ from Sigma-Aldrich (St. Louis, USA), methanol (HPLC grade) from VWR BDH Prolabo (Fontenay-sous-Bois, France) and hydrochloric acid (37\% for analysis, ACS Merck) were used in solid phase extraction (SPE). The SPE columns were Supelclean $^{\text {TM }}$ LC-Si SPE tubes $3 \mathrm{~mL}$ from Supelco (Pennsylvania, USA) and Oasis WCX $6 \mathrm{cc}$ cartridge $150 \mathrm{mg}$ from Waters (Dublin, Ireland).

Syringe filters with $0.2 \mu \mathrm{m}$ PTFE membrane were purchased from VWR (West Chester, USA).

\subsection{Instrumentation}

\subsubsection{LC-DAD}

Chromatographic analysis of PQ by LC-DAD was performed in a Hitachi Elite LaChrom (Darmstadt, Germany) with a L-2130 pump, a L-2200 autosampler and a L-2455 diode array detector (DAD). For $P Q$ concentrations between $0.1 \mathrm{mg} / \mathrm{L}$ and $80 \mathrm{mg} / \mathrm{L}$, quantification was done by direct injection of $99 \mu \mathrm{L}$ in a Purospher $^{\circledR}$ STAR LiChroCART ${ }^{\circledR}$ RP-18 endcapped $(240 \times 4 \mathrm{~mm}, 5 \mu \mathrm{m})$ reversed phase column from Merck (Darmstadt, Germany) and using a mobile phase of $80 \%(\mathrm{v} / \mathrm{v})$ of $10 \mathrm{mM}$ HFBA in water and $20 \%(\mathrm{v} / \mathrm{v})$ of acetonitrile $(A C N)$, at isocratic conditions, with a flow rate of $1 \mathrm{~mL} / \mathrm{min}$. For lower $P Q$ concentrations, the chromatographic separation was achieved by a Chromolith $^{\circledR}$ Performance RP-18e 100-3 (3x4.6 mm) column from Merck (Darmstadt, Germany). The mobile phase used was composed by $95 \%$ of HFBA $10 \mathrm{mM}$ and $5 \%$ of $A C N$ at $1 \mathrm{~mL} / \mathrm{min}$ under isocratic conditions. PQ quantification was done at $259 \mathrm{~nm}$ in both cases.

\subsubsection{LC-MS}


Chromatographic analyses were performed using a Varian LC-MS system (Lake Forest, USA) constituted by a ProStar 210 Binary Solvent Delivery Module and a 500-MS LC Ion Trap Mass Spectrometer equipped with an electrospray ionization source (ESI). Data was acquired and processed by Varian MS Workstation Version 6.9 software. A Polaris ${ }^{\circledR}$ C18-A column ( $50 \mathrm{~mm} \times 2 \mathrm{~mm}$ i.d., particle size: $5 \mu \mathrm{m}$ ) in combination with a MetaGuard column Pursuit ${ }^{\circledR}$ C18 (10 mm x $2.0 \mathrm{~mm}$ i.d., particle size: $5 \mu \mathrm{m}$ ) were supplied by Varian (Lake Forest, USA). The mobile phase was composed of $5 \mathrm{mM}$ HFBA in water $(80 \%, \mathrm{v} / \mathrm{v})$ and methanol $(20 \%, v / v)$, running in isocratic conditions. The analyses were done in the positive ion mode. The flow rate was $0.2 \mathrm{~mL} / \mathrm{min}$ and the injection volume was $10 \mu \mathrm{L}$. The MS conditions were optimized during the experimental work, and the final conditions were: $\mu$ Scan average $-3 \mu$ scans, drying gas -20 psi at $400{ }^{\circ} \mathrm{C}$, nebulising gas -50 psi, multiplier offset $-300 \mathrm{~V}$, needle voltage $-3839 \mathrm{~V}$, capillary voltage $-87 \mathrm{~V}$, RF loading $77 \%$.

\subsection{SPE procedure for the SPE-LC-DAD method}

In this methodology, one litre of $\mathrm{PQ}$ standard $(10 \mu \mathrm{g} / \mathrm{L})$ at $\mathrm{pH} 9$ (adjusted with $\mathrm{NaOH}$ ) is passed through a cartridge (silica or Oasis WCX waters), where the analyte is retained. After that, $3 \mathrm{~mL}$ of a solvent $(\mathrm{HCl} 0.1 \mathrm{M}$ in methanol, $\mathrm{HCl} 6 \mathrm{M}$ in methanol or saturated solution of $\mathrm{NH}_{4} \mathrm{Cl}$ in methanol) is used to elute paraquat. After solvent evaporation under nitrogen flow, the sample was reconstituted in $1 \mathrm{~mL}$ of distilled water and was injected in the HLPC-DAD (enrichment factor is 1000x).

\subsection{Validation parameters}


The validation of the analytical methods and the uncertainty measurement followed the bottom-up approach described in the Eurachem CITAC Guide ${ }^{[14]}$ and by other authors ${ }^{[15-}$ ${ }^{17]}$. It comprised a first step of in-house validation, where the main parameters were obtained - linearity of the response, limit of detection (LOD) and limit of quantification (LOQ), precision and accuracy. Precision was assessed by repeatability and intermediate precision for both DI-LC-DAD and DI-LC-MS methods at three PQ concentration levels. Precision of the SPE-LC-DAD method was only evaluated by repeatability at $0.2,10$ and 50 $\mu \mathrm{g} / \mathrm{L}$ of $\mathrm{PQ}$. Results were expressed as the coefficient of variation (CV\%) of different replicate measurements. Accuracy was investigated by testing the analytical response capability in the presence of other species or compounds. For DI-LC-DAD method a wide range of interference scenarios were considered and, for that reason, a detailed explanation is given in section 2.4.1. The accuracy of the SPE-LC-DAD method was determined comparing the obtained concentration of $P Q$ by the calibration curve (after SPE extraction) with the expected concentration, for a specific spiking level. Concerning the DI-LC-MS method, the accuracy was evaluated by comparing the analytical responses (obtained concentration by calibration curve versus expected concentration) for PQ standards prepared in distilled water and in river water.

The second step of the validation is the estimation of the uncertainty associated to the results, using the other parameters as an assumption that they represented the main sources of uncertainty to the final result.

\subsubsection{Recovery assays for the DI-LC-DAD method}

Recovery assays were performed by the standard addition method at three PQ concentration levels $(0.25,30$ and $80 \mathrm{mg} / \mathrm{L})$. Since the developed method should be able 
to answer in different real scenarios, the analytical response under different water matrices was evaluated: tap water, water after contact with different kind of deposits (herein called S2, S3 and S4), clay and water after cells exposition. The applicability of this method to quantify PQ in waters contaminated with GMX was also evaluated.

\subsubsection{Tap water}

Tap water was used to prepare a PQ standard and the analytical response was compared with that obtained when the standard was prepared in distilled water.

\subsubsection{Gramoxone}

The analytical response was evaluated when one PQ commercial product (GMX) was added to an aqueous sample. First, a GMX solution was prepared and the analytical response was obtained. Then, a known amount of PQ analytical standard was added and the recovery was calculated by comparison of the obtained and expected mass of PQ.

\subsubsection{Deposits}

The deposit samples (S2, S3 and S4) used in the recovery tests were supplied by Dr. Gabriela Schaule (IWW Water Centre, Germany). The deposits were removed from real cast iron pipes that needed to be replaced. Deposits were submitted to dryness in an oven (till no weight variation has been detected). Then, all deposits were sieved and were kept in dry conditions until the experiments. An extensive physico-chemical characterization of these deposits has been described previously ${ }^{[18]}$ and, for that reason, the nomenclature used in such study was maintained. According to the results obtained in that study, it was possible to classify the S2, S3 and S4 samples as brown, tubercle and 
white deposits, respectively, being representative of the main classes of deposits formed in drinking water networks ${ }^{[18]}$. Clay was the other sample used in this test. The main properties of all deposits and clay used are summarized in Table 1. Clay chemical composition was obtained from LNEG (Laboratório Nacional de Energia e Geologia, Portugal) and the particle size was determined by a Coulter Counter LS 230 with small volume model. The pHpzc (point of zero charge) was obtained as for deposits ${ }^{[18]}$.

The organic matter content was determined in a TOC-VCSH apparatus with a solid sample module SSM-5000A. The total surface area was determined by mercury porosimetry. For recovery assays, a known amount of deposit $(300 \mathrm{mg})$ was put in contact with water $\left(10 \mathrm{~mL}\right.$ ), at $20^{\circ} \mathrm{C}$ in the dark during $24 \mathrm{~h}$ (batch conditions). After filtration, the water was used to prepare a $\mathrm{PQ}$ standard and the analytical response was compared with that obtained when the standard was prepared in distilled water.

\subsubsection{Cells}

A sterile concentrated medium composed by $5.50 \mathrm{~g} / \mathrm{L}$ of glucose, $2.50 \mathrm{~g} / \mathrm{L}$ of peptone, $1.25 \mathrm{~g} / \mathrm{L}$ of yeast extract, $1.88 \mathrm{~g} / \mathrm{L}$ of $\mathrm{KH}_{2} \mathrm{PO}_{4}$ and $2.60 \mathrm{~g} / \mathrm{L}$ of $\mathrm{Na}_{2} \mathrm{HPO}_{4}$ was inoculated with a culture of Pseudomonas fluorescens grown on plate count agar (PCA) medium at $37{ }^{\circ} \mathrm{C}$ overnight. Cell suspension was incubated overnight at $37{ }^{\circ} \mathrm{C}$ on an orbital shaker and, in the next day, they were washed with a phosphate buffer solution under sterile conditions. The optical density of the final suspension was 0.4. Then, the cells were removed by centrifugation and by filtration using a PTFE syringe filter. Recovery tests were performed at three PQ concentration levels by the addition of a known amount of $P Q$ to the filtrate. The analytical responses were compared with that obtained when the same amount of PQ was added to distilled water. 


\subsection{Interference studies of Fenton's species on PQ quantification by DI-LC- DAD}

A stock solution of $\mathrm{Fe}(\mathrm{II})$ was prepared by dissolving an appropriate amount of $\mathrm{FeSO}_{4}$ in water, adjusting the $\mathrm{pH}$ to 3 . The $\mathrm{Na}_{2} \mathrm{SO}_{3}$ and the $\mathrm{H}_{2} \mathrm{O}_{2}$ were measured directly from the commercial reagents to prepare the standards. First of all, independent solutions of the Fenton's species were injected and the DAD response was analysed. Then, solutions containing both PQ and Fenton's species (individually) were prepared and injected. Two $\mathrm{Fe}(\mathrm{II})$ concentrations were considered $\left(3.6 \times 10^{-4}\right.$ and $\left.6.4 \times 10^{-4} \mathrm{M}\right)$ and interference tests with this chemical were made for 1,5 and $80 \mathrm{mg} / \mathrm{L}$ of PQ. The interference of $\mathrm{Na}_{2} \mathrm{SO}_{3}$ and $\mathrm{H}_{2} \mathrm{O}_{2}$ on the analytical response was assessed for $1,5,20,50,70$ and $80 \mathrm{mg} / \mathrm{L}$ of PQ. The concentrations of $\mathrm{Na}_{2} \mathrm{SO}_{3}\left(9.6 \times 10^{-3}, 3.9 \times 10^{-2}, 9.6 \times 10^{-2}, 2.0 \times 10^{-1}\right.$ and $\left.3.4 \times 10^{-1} \mathrm{M}\right)$ and $\mathrm{H}_{2} \mathrm{O}_{2}$ $\left(3.4 \times 10^{-2}\right.$ and $\left.5.7 \times 10^{-2} \mathrm{M}\right)$ used in interference tests are in accordance with the PQ degradation study by classic Fenton already published ${ }^{[13]}$. The same is applicable to Fe(II) concentrations.

\section{Results and discussion}

\subsection{Validation of the DI-LC-DAD method for high PQ concentrations}

In case of a deliberate contamination, the PQ concentrations in drinking water should be at relatively high levels (of $\mathrm{mg} / \mathrm{L}$ order of magnitude). So, the goal of this section was to develop an analytical methodology by LC-DAD able to quantify high PQ concentrations in a short time. The applicability of this method was evaluated by testing its response to waters contaminated with paraquat, after being in contact with deposits or cells. These experiments intend to represent the worst case scenario related to the release of some 
components from these two matrices to the drinking water, during its normal flow in drinking water networks. Additionally, the $P Q$ analytical response obtained with this method was evaluated in the presence of other compounds, as occurred when GMX is used as contamination agent. Finally, the influence of some species (such as Fe(II), $\mathrm{H}_{2} \mathrm{O}_{2}$ and $\mathrm{Na}_{2} \mathrm{SO}_{3}$ ) used in the treatment of paraquat contaminated waters by Fenton's reagent was assessed.

\subsubsection{Linearity range and limits of detection and quantification}

Although the temperature of the analytical column was kept constant during the chromatographic analysis, retention time of the analyte slightly changed $(5.7 \pm 0.3 \mathrm{~min})$ due to the presence of other compounds/ species, more specifically in real samples. False $P Q$ peak identification was overcome by regular injection of an analytical control standard and by analysis of the herbicide absorption spectrum, which allowed the evaluation of the purity of the peaks obtained.

Calibration was performed by direct injection of ten $P Q$ analytical standards. The linearity range considered was from 0.1 to $80 \mathrm{mg} / \mathrm{L}$ of $\mathrm{PQ}$. The calibration curve obtained, when the standards were injected at least twice, and the respective $98 \%$ confidence range are presented in Figure 1. The limits of detection and quantification were calculated, based on a signal-to-noise ratio $(\mathrm{S} / \mathrm{N})$ of 3 and 10 , and were 0.01 and $0.03 \mathrm{mg} / \mathrm{L}$, respectively. Only one study was found in the literature concerning the direct injection of a $P Q$ standard in a LC-UV and a LOD of $2 \mathrm{mg} / \mathrm{L}$ of $\mathrm{PQ}$ was obtained ${ }^{[19]}$, which is much higher than the obtained here. To the author's best knowledge, none study of paraquat quantification in water by DI-LC-DAD was published. 
A relative standard deviation of the slope of $0.7 \%$ and a correlation coefficient of 0.9996 were obtained. It was also verified that the confidence limits for the intercept contains the origin $(b-s b<0<b+s b$, where $b$ is the intercept and $s b$ is the standard deviation of the intercept of the regression line). Those results prove the adequacy of the calibration curve for the purpose of analysis ${ }^{[20]}$.

\subsubsection{Precision}

Precision was evaluated by repeatability and intermediate precision and was expressed as the coefficient of variation (CV\%) of different replicate measurements. Repeatability expresses the analytical response variability observed when, at least, six intra-day measurements were performed for a certain standard and under the same conditions. Intermediate precision indicates the analytical response variation observed when one of the factors is changed (in this case the day of injection). The last one was evaluated based on at least six replicates. Precision was assessed at three PQ concentrations $(0.25,30$ and $80 \mathrm{mg} / \mathrm{L}$ ) and presented in Table 2 . As can be seen, there are higher variations in the response for lower $\mathrm{PQ}$ concentrations but, for higher ones the precisions are well below $10 \%$.

\subsubsection{Accuracy}

Accuracy is defined as a measure of the closeness between one analytical result and the true value. This parameter could be assessed comparing the analytical response for a certified reference material with the value indicated by the supplier. Alternatively, this parameter can be evaluated by the standard addition method. By this way, as the name itself mentions, a known amount of $P Q$ is added to a sample and then, the expected and 
obtained responses are compared. For accuracy assessment, recovery assays were performed at three $P Q$ concentration levels $(0.25,30$ and $80 \mathrm{mg} / \mathrm{L})$ and considering different scenarios.

The water into the pipes is constantly in contact with deposits with different compositions depending on the pipe material, water characteristics and region where it is located. Despite of the large heterogeneity of deposits formed along drinking water networks, it is assumed that these deposits may be classified in accordance with the three categories proposed by Echeverría and co-workers (brown, tubercle and white deposits) ${ }^{[21]}$. For that reason, three different deposits from real drinking water networks, one of each category, were considered for recovery experiments, as well as clay, which were analyzed in a previous published work ${ }^{[22]}$. The possibility of some compounds (inorganic and organic) present in these deposits/clay leach to the water phase and interfere in the analytical method response was screening. The same tests were performed with water after being in contact with cells (Pseudomonas fluorescens). This was the best available approximation to represent the effect of the biofilm that grows in drinking water networks. The analytical method response was also evaluated for a different type of water (tap water).

The applicability of the DI-LC-DAD method to quantify $P Q$ in waters, when a PQ commercial formulation (GMX) is used as contamination agent, was also assessed. Although the composition of the commercial mixture was known, the purity in terms of PQ was confirmed by the standard addition method. By this way, increasing amounts of $\mathrm{PQ}$ analytical standard were added to a constant amount of $\mathrm{GMX}{ }^{[23]}$. The content of $\mathrm{PQ}$ was determined by the interception of the DAD response for the prepared samples with 
the independent variable axis. It was verified that there are $27 \pm 2 \mathrm{mg}$ of $P Q$ per $100 \mathrm{mg}$ of GMX. This result confirms the value supplied by Syngenta, which is 25.6 wt.\%.

The recovery values obtained for all referred situations are indicated in Table 3. Generally the recovery percentages obtained are acceptable, except for the experiments with S2 deposit and cells at the lowest spiking level. Recoveries on average of 77,99 and $101 \%$ were attained for $0.25,30$ and $80 \mathrm{mg} / \mathrm{L}$ of $P Q$ by this method, respectively. The recovery of $23 \%$ and $6 \%$, respectively for S2 and Cells, were achieved for the lowest concentration levels of the calibration curve, where the higher uncertainty exists (see section 3.1.4).

\subsubsection{Estimation of the global uncertainty associated to the DI-LC-DAD method} To evaluate the global uncertainty associated to the quantification of PQ in water by DILC-DAD, the bottom-up approach was used. This methodology was proposed by the International Organization for Standardization (ISO) and adopted by EURACHEM/CITAC Guide ${ }^{[14]}$. The most significant sources of uncertainty that are thought to affect the final result are: the uncertainty associated with the preparation of the standards (U1), to the calibration curve (U2), the uncertainty associated to the precision of the extraction and also of the chromatographic method (U3) and to the accuracy (U4). The contribution of these four individual uncertainties to the global uncertainty is depicted in Figure 2. As illustrated, for PQ concentrations lower than $5 \mathrm{mg} / \mathrm{L}$, the main source of uncertainty is the uncertainty associated to the calibration curve (U2). On the other hand, for higher concentrations of analyte, the accuracy (U4) is the main responsible for the variation of the response. Standard preparation (U1) contributes always with less than $10 \%$ for the global uncertainty. Precision (U3) has the same behavior of accuracy (U4): the higher the analyte concentration, the higher the precision and accuracy contributions. Global 
uncertainty below $13 \%$ was found for the most part of the calibration range (Figure 2). However, when concentrations approach the detection limits of the analytical method, assessed global uncertainty increases and represents more than $100 \%$ of the stated value. For that reason, Figure 2 only represents the global uncertainty for paraquat dichloride concentrations higher than $1 \mathrm{mg} / \mathrm{L}$.

The main advantages of the DI-LC-DAD method are the simplicity and rapidity of the determination, because results may be obtained in few minutes, with good accuracy and precision. The equipment is also common in most analytical laboratories, which is very important in an emergency situation. However some drawbacks should be pointed out:

1) Detection limit $(10 \mu \mathrm{g} / \mathrm{L})$ is higher than maximum legal limit $(0.1 \mu \mathrm{g} / \mathrm{L})$; however in the event of a deliberate contamination this is an excellent method for rapid detection;

2) A significant uncertainty is found near the limit of detection of the method and up to $1 \mathrm{mg} / \mathrm{L}$;

3) Possibility of co-elution of other contaminants and therefore an unequivocal identification of the contaminant cannot be assessed, unless other methods are used for confirmation purposes, as LC-MS.

\subsubsection{Specificity of the method - study of interferences from Fenton's reaction}

This topic is particularly important when water samples have to be analysed following a decontamination procedure using a chemical method, as it happens with the decontamination by Fenton's reagent ${ }^{[13]}$. The interference of chemicals used in the Fenton's reaction, such as $\mathrm{H}_{2} \mathrm{O}_{2}, \mathrm{FeSO}_{4}$ and $\mathrm{Na}_{2} \mathrm{SO}_{3}$, on the analytical method response was studied. It was assumed that these species interfere with the measurement of PQ by 
DI-LC-DAD if the variation of the paraquat peak area was superior to the global uncertainty for the considered PQ contamination level.

It is important to highlight the novelty of this research topic since, up to the author knowledge it was never addressed in any other study reported in open scientific literature.

\subsubsection{Iron salt}

The effect of Fe (II) was assessed by evaluating the PQ analytical response in the presence of two $\mathrm{FeSO}_{4}$ concentrations at different $\mathrm{PQ}$ contamination levels. Figure 3 shows the variation of the $P Q$ peak area in relation to the value achieved for a $P Q$ standard prepared in water. As can be checked from Figure 3, variations of the PQ peak area are below the estimated global uncertainty for the correspondent $P Q$ contamination level. For that reason, it can be concluded that there is no influence of the iron salt in the $P Q$ quantification by the proposed method.

\subsubsection{Sodium sulfite and hydrogen peroxide}

Regarding the interference of $\mathrm{Na}_{2} \mathrm{SO}_{3}$, which is added to quench the reaction, it can be observed from Figure 4 that it depends on the concentration of this species in solution. The variation of the $P Q$ peak area is below the global uncertainty for the three lower concentrations of $\mathrm{Na}_{2} \mathrm{SO}_{3}\left(9.6 \times 10^{-3}, 3.9 \times 10^{-2}\right.$ and $\left.9.6 \times 10^{-2} \mathrm{M}\right)$. However, for the two higher ones $\left(2.0 \times 10^{-1}\right.$ and $\left.3.4 \times 10^{-1} \mathrm{M}\right)$, the variations of the $P Q$ peak area are clearly above the estimated global uncertainty $(12 \%$ for $5 \mathrm{mg} / \mathrm{L}$ of $\mathrm{PQ}$ and approximately $7 \%$ for higher PQ concentrations). The observed variations are consequence of significant decreases on $\mathrm{PQ}$ peak areas in the presence of high concentrations of $\mathrm{Na}_{2} \mathrm{SO}_{3}$. The 
interference in the analytical response may be explained by the shift effect, in the maximum wavelength or in the absorbance signal, which a molecule suffers in the presence of other chemical species. The bathochromic or hypsochromic shift is the change of spectral band position in the absorption spectrum of a molecule to a longer or shorter wavelength, respectively. This can occur because of a change in environmental conditions, for example, or a change in solvent polarity. On the other hand, the hypsochromic shift is the reduction of the intensity of the absorption band.

So, it means that higher concentrations of $\mathrm{Na}_{2} \mathrm{SO}_{3}$ may interfere with the measurement of $P Q$ concentration in waters by the proposed method. Because of the decrease on the $P Q$ peak area, calibration curves were obtained in the absence and in the presence of the two major concentrations of $\mathrm{Na}_{2} \mathrm{SO}_{3}$ studied, where influence was verified (Figure 5). Figure 5 clearly shows that the quantification of $\mathrm{PQ}$ in the presence of $\mathrm{Na}_{2} \mathrm{SO}_{3}$ needs to be corrected by a conversion factor depending on the concentration of this specie. $\mathrm{H}_{2} \mathrm{O}_{2}$ is consumed along the Fenton's reaction and its concentration was not monitored along the experiments. Although its concentration was becoming lower with the reaction time, the amount of $\mathrm{Na}_{2} \mathrm{SO}_{3}$ added to quench the reaction, whenever a sample was withdrawn, was kept constant. The amount of $\mathrm{Na}_{2} \mathrm{SO}_{3}$ added corresponds to an excess of six times related to the amount of $\mathrm{H}_{2} \mathrm{O}_{2}$ used in the experiment. So, the best and worst case scenarios were considered for interference assays with $\mathrm{H}_{2} \mathrm{O}_{2}$. In other words, the best situation corresponds to a $\mathrm{H}_{2} \mathrm{O}_{2}$ absence and the worst one to the presence of all $\mathrm{H}_{2} \mathrm{O}_{2}$ dose added in the experiment at the beginning of the process. For time consuming reasons, only the two higher $\mathrm{H}_{2} \mathrm{O}_{2}$ concentrations were studied (which corresponds also to the two higher $\mathrm{Na}_{2} \mathrm{SO}_{3}$ concentrations) because if there were not influence on the analytical response under these conditions it means that there were not at lower $\mathrm{H}_{2} \mathrm{O}_{2}$ 
concentration levels. As can be checked from Figure 4, the presence of $\mathrm{H}_{2} \mathrm{O}_{2}$ has no effect on the PQ peak area. Despite of the interference of high doses of $\mathrm{Na}_{2} \mathrm{SO}_{3}\left(2.0 \times 10^{-1}\right.$ and $3.4 \times 10^{-1} \mathrm{M}$ ) on the analytical response, is important to highlight that for the optimum $\mathrm{PQ}$ degradation conditions $\left(\left[\mathrm{Fe}^{2+}\right]_{0}=5.0 \times 10^{-4} \mathrm{M},\left[\mathrm{H}_{2} \mathrm{O}_{2}\right]_{0}=1.6 \times 10^{-2} \mathrm{M}\right.$ and $\left[\mathrm{Na}_{2} \mathrm{SO}_{3}\right]=9.6 \times 10^{-}$ $\left.{ }^{2} \mathrm{M}\right)^{[13]}$, there is no influence of Fenton's species on the PQ quantification by DI-HLPCDAD.

\subsection{Validation of the SPE-LC-DAD method for low PQ concentrations}

As referred before, the DI-LC-DAD method has as disadvantage a limit of detection higher than the EU legislated value $(0.1 \mu \mathrm{g} / \mathrm{L})$. To ensure that $\mathrm{PQ}$ in water is lower than the established limit, an analytical methodology was developed to quantify paraquat at low concentrations. For that, it was necessary to optimize a pre-concentration step prior to the injection in the LC-DAD.

\subsubsection{Extraction technique}

Solid phase extraction was the extraction methodology selected for this study because it has been the most used procedure for clean-up and isolation of $P Q$ from water matrices. Concerning the packing materials used in SPE, it was decided to test silica and a cation exchange resin. Silica was chosen because it is one of the most polar sorbents available for SPE and proved to be a valid option for analysis of quaternary ammonium (QA) compounds like $P Q^{[24-31]}$. The Oasis WCX sorbent, which is a polymeric reversed-phase, weak ion exchange mixed-mode sorbent, was also considered because it was designed for highly selective sample preparation of strong basic compounds and quaternary amines. 
For the experiments with silica, the $\mathrm{pH}$ of the $\mathrm{PQ}$ aqueous solution was adjusted to 9 before the loading step because it is well known that QA compounds are largely retained on silica under neutral or slightly basic conditions ${ }^{[24]}$. It was reported that recoveries for diquat, paraquat and difenzoquat are quite acceptable in the $\mathrm{pH}$ 6.5-9.5 range ${ }^{[24]}$. The same procedure was adopted for Oasis WCX sorbent because, according to the manufacturer, $\mathrm{PQ}$ is eluted from this sorbent at low $\mathrm{pH}$ (almost $100 \%$ for $\mathrm{pHs}$ lower than $\mathrm{pH} 2)^{[32]}$.

For the elution step, three solvents were considered: $\mathrm{HCl} 0.1 \mathrm{M}$ in methanol, $\mathrm{HCl} 6 \mathrm{M}$ in methanol and saturated ammonium chloride in methanol. The acidic eluents were included in the list because as the QA compounds are retained in the sorbent under neutral or slightly basic conditions, it is expected that they will desorb under acidic medium. In particular, hydrochloric acid has been used as eluent in SPE pre-concentration procedures for $P Q$ in waters $[25,26,29]$. Methanol $(\mathrm{MeOH})$ was tested because it is sometimes applied in some eluents to desorb PQ from a wide range of SPE sorbents: silica ${ }^{[25-31]}$, graphitized carbon black ${ }^{[33]}$, resin ${ }^{[34]}$, alumina ${ }^{[35]}$. On the other hand, $\mathrm{MeOH}$ has lower boiling point than water and so, the pre-concentration step of the final extract by solvent evaporation is facilitated. Ammonium compounds such as ammonium sulphate ${ }^{[27,28,31,33]}$, ammonium chloride ${ }^{[34]}$, ammonium formate ${ }^{[36]}$ and ammonium hydroxide ${ }^{[37]}$ have been widely used to elute PQ in SPE. Saturated ammonium chloride is often used as PQ displacement agent in other matrices such as soils ${ }^{[38,39]}$. For that reason, saturated ammonium chloride was selected.

The results obtained when $1 \mathrm{~L}$ of $\mathrm{PQ}$ aqueous solution $(10 \mu \mathrm{g} / \mathrm{L})$ was loaded through silica or Oasis WCX sorbents and the three above-mentioned eluents were used are outlined in Figure 6. 
The extraction percentages were calculated comparing the analytical response obtained when a $10 \mathrm{mg} / \mathrm{L} P Q$ standard was directly injected in the LC-DAD with the one obtained when a $10 \mu \mathrm{g} / \mathrm{L} \mathrm{PQ}$ standard was extracted (concentration factor of $1000 \mathrm{x}$ ) prior to the injection. As can be seen, higher extraction percentages are attained when Oasis WCX cartridge was used. As $\mathrm{HCl} 0.1 \mathrm{M}$ in $\mathrm{MeOH}$ is sufficient to obtain acceptable extraction percentages, this solvent was used in the following experiments.

\subsubsection{Quantitative analysis}

The calibration curve comprised seven concentration levels, in the range of 0.1 to $50 \mu \mathrm{g} / \mathrm{L}$ of PQ. Good linearity was obtained in the concentration range studied ( $R=0.9989)$. Quantitative parameters were obtained from the calibration curve and are indicated in Table 4. The limits of detection and quantification were calculated based on a signal-tonoise ratio $(\mathrm{S} / \mathrm{N})$ of 3 and 10 and are 0.04 and $0.1 \mu \mathrm{g} / \mathrm{L}$, respectively. The LOD of $0.04 \mu \mathrm{g} / \mathrm{L}$ of $P Q$ is of the same order of magnitude ${ }^{[28,30,31,33]}$ or lower ${ }^{[27,29,37]}$ than the values reported in other studies of the literature.

The relative standard deviation of the slope was $1.5 \%$ and the correlation coefficient of the calibration curve was 0.9989 . It was also verified that the confidence limits for the intercept contains the origin $(b-s b<0<b+s b$, where $b$ is the intercept and $s b$ is the standard deviation of the intercept of the regression line). Again, and according to these results, it can be concluded that the calibration curve is adequate for the purpose of this analysis ${ }^{[20]}$.

\subsubsection{Precision and accuracy}


Precision was evaluated by six consecutive injections of extracts obtained from the concentration of $\mathrm{PQ}$ analytical standards by SPE. The precision was inspected at three PQ concentration levels and the results, expressed as relative standard deviation, were 8.9, 1.4 and $0.5 \%$ for $0.2,10$ and $50 \mu \mathrm{g} / \mathrm{L}$, respectively.

Accuracy of this methodology was estimated comparing the PQ concentration level obtained from the calibration curve with the real $P Q$ concentration in the water. This parameter was evaluated at two $\mathrm{PQ}$ concentration levels - 10 and $50 \mu \mathrm{g} / \mathrm{L}$. Recoveries were on average 84 and $101 \%$ for 10 and $50 \mu \mathrm{g} / \mathrm{L}$ levels, respectively.

3.2.4 Estimation of the global uncertainty associated to the SPE-LC-DAD method The global uncertainty associated to the quantification of PQ in water by SPE-LC-DAD was also estimated by the bottom-up approach/EURACHEM ${ }^{[14]}$. From Figure 7, it can be seen that the uncertainty associated to the calibration curve (U2) represents the main source of uncertainty, particularly for lower PQ concentration levels. For higher PQ concentrations, the weight of the uncertainty associated to the precision (U3) for the overall uncertainty is comparable to that attained for the uncertainty associated to the calibration curve (U2). The uncertainties associated with the preparation of the standards (U1) and accuracy (U4) increase for higher PQ contamination degrees, but minimal relative individual contributions to the total uncertainty were estimated.

As shown in Figure 7, the lower the concentration level, the higher is the uncertainty associated to the results. Global uncertainty below $11 \%$ was found for PQ concentrations higher than $5 \mu \mathrm{g} / \mathrm{L}$ (Figure 7). However, in the vicinity of the LOD of the analytical method, assessed global uncertainty increases and represents more than $100 \%$ of the 
stated value. For that reason, Figure 7 only represents the global uncertainty for $P Q$ concentrations higher than $1 \mu \mathrm{g} / \mathrm{L}$.

\subsection{Validation of the DI-LC-MS method for confirmation purposes}

A drawback of the LC-DAD methods is the impossibility of the unequivocal identification of the contaminants/ oxidation by-products. The solution is to use an alternative method for confirmation purposes. That is to say, in the event of detecting a possible contamination by the rapid method (LC-DAD), a confirmation needs to be done by LCMS.

Paraquat may be analysed by direct injection in LC-MS in less than 5 minutes. This is the main advantage, besides the fact that it is the only method that imparts an unequivocal identification of the detected analyte, although the equipment is extremely expensive and its use is reserved to high-skilled and trained technicians.

\subsubsection{Solvents/ Mobile phase selection}

Charged quaternary amines, such as paraquat, exhibit little retention on C18 or other alkyl stationary phases and therefore a mobile phase modifier (ion-pairing reagent) needs to be added to increase the interactions between paraquat and the stationary phase, providing the necessary retention and resolution. For compatibility with MS detection, however, a volatile mobile phase is needed and, therefore, low concentrations of HFBA effectively shield the positive charges of paraquat, increasing interactions between the quaternary amines and the stationary phase.

\subsubsection{MS optimization procedures}


The optimization of MS is achieved in three steps: mass, ionization source and chromatographic optimization.

Firstly, a PQ standard solution $(5 \mathrm{mg} / \mathrm{L}$ ) was direct-infused in the electrospray mass spectrometer. This procedure allowed obtaining the mass fragmentation pattern of $P Q$, as well as, the parent ion. The most abundant peaks were the singly charged molecular ion $[\mathrm{M}]^{+\bullet}\left(m / z\right.$ 186) and the deprotonated molecule $[\mathrm{M}-\mathrm{H}]^{+}(m / z \quad 185)$. The highest predominant ion which results from the fragmentation of $[\mathrm{M}-\mathrm{H}]^{+}$was the $\left[\mathrm{M}-\mathrm{CH}_{3}\right]^{+}(\mathrm{m} / \mathrm{z}$ 171) one.

The mass optimization was carried out by evaluating the MS response when the capillary voltage, the needle voltage and the RF loading were changing at a time while the others were kept constant (single factor-at-a-time approach). The value which gave the best single factor-at-a-time MS response was considered the optimal condition for the parameter under study. Finally, for the best individual conditions the excitation amplitude $\mathrm{CID}$ was set. The shield voltage was set at $600 \mathrm{~V}$, according to the manufacturer. The optimal values for each parameter are compiled in Table 5.

The optimal condition for the temperature of the drying gas, as well as, the best drying and nebulization gas pressures were determined by direct injection of a $P Q$ standard solution $(5 \mathrm{mg} / \mathrm{L})$ in combination with the mobile phase $(0.2 \mathrm{~mL} / \mathrm{min})$. The mobile phase was $50 \%$ HFBA $5 \mathrm{mM}$ and $50 \% \mathrm{MeOH}$. Again, the best conditions represent the best individual MS responses by varying each parameter at a time (Table 5). The drying and the nebulization gas pressures are related to the flow rate of the mobile phase. Typically, values between $0.2-0.3 \mathrm{~mL} / \mathrm{min}$ for the flow rate of the mobile phase were used in LC-MS analysis. Therefore, according to the manufacturer' reference values, the nebulization gas 
pressure should be higher than 40 psi and the drying gas pressure should range from 15 to 45 psi.

To optimize the chromatographic conditions, a $P Q$ analytical standard $(5 \mathrm{mg} / \mathrm{L}$ ) was injected in a C18 column, under the conditions optimized previously. The influence of the amount of methanol in the mobile phase on the LC-MS response was studied. The maximum MS response was attained when $20 \%$ of $\mathrm{MeOH}$ and $80 \%$ of HFBA 5 mM were used. Under these conditions, the retention time for PQ was $4.7 \mathrm{~min}$.

\subsubsection{Linearity and limits of detection and quantification}

The calibration curve for determination of $P Q$ in water by LC-MS was obtained with ten $\mathrm{PQ}$ analytical standards (from 0.1 to $10 \mathrm{mg} / \mathrm{L}$ ). The analytical standards were directly injected in the LC-MS, at least twice, with a coefficient of variation in the range of 1.9 9.4\%. The calibration curve and the respective $98 \%$ confidence range are presented in Figure 8. The quantitative information about the method developed in LC-MS is presented in Table 6. As observed in the other proposed methods, LC-MS method is also suitable to be applied in a quality control laboratory because the relative standard deviation of the slope is lower than $5 \%$, the correlation coefficient is higher than 0.995 and the confidence limits for the intercept contains the origin $(b-s b<0<b+s b$, where $b$ is the intercept and $s b$ is the standard deviation of the intercept of the regression line) ${ }^{[20]}$. The limits of detection and quantification were determined based on a signal-to-noise ratio (S/N) of 3 and 10 and were 20 and $60 \mu \mathrm{g} / \mathrm{L}$, respectively. Similar LODs (7-25 $\mu \mathrm{g} / \mathrm{L})$ were found in the literature for DI-LC-MS methods ${ }^{[40-42]}$.

\subsubsection{Precision and accuracy}


Precision of the PQ analytical method by LC-MS was assessed by repeatability and intermediate precision. Repeatability was determined by six consecutive injections of three $P Q$ analytical standards $(0.2,5$ and $10 \mathrm{mg} / \mathrm{L})$. The intermediate precision was evaluated for the same $P Q$ concentration levels and corresponds to the injection of each standard in three days. The results expressed as relative standard deviation are shown in Table 7. Accuracy was evaluated comparing the analytical response for a standard prepared in distilled water with that obtained for a standard prepared in river water (Rio Ave). This parameter was assessed in triplicate at three PQ concentrations: $0.2,5$ and 10 $\mathrm{mg} / \mathrm{L}$. Recoveries were $94 \pm 10,101 \pm 11$ and $96 \pm 7$ for $0.2,5$ and $10 \mathrm{mg} / \mathrm{L}$ of $P Q$.

\subsubsection{Estimation of the global uncertainty associated to the LC-MS method} The global uncertainty associated to the results obtained by the proposed LC-MS method was estimated by the bottom-up approach/EURACHEM. Figure 9 depicts the contribution of each individual source of uncertainty for the overall uncertainty. As demonstrated, the uncertainty of a result is mainly dependent on the uncertainty associated to the calibration curve (U2) for low PQ concentrations. However, this source of uncertainty contributes only with $12 \%$ to the total uncertainty at high PQ concentration degrees while the uncertainties associated to precision (U3) and accuracy (U4) with around $80-85 \%$. The uncertainty associated to the preparation of the standards (U1) is minimal in the overall range of concentrations.

The global uncertainty for all PQ linearity range $(0.1$ to $10 \mathrm{mg} / \mathrm{L})$ is illustrated in Figure 9. As observed in Figure 9, the global uncertainty is around 6\% for PQ concentrations higher than $3 \mathrm{mg} / \mathrm{L}$ (the most part of the linearity range). For lower concentrations, the global 
uncertainty associated to the results increase exponentially. In short, this method proved to be reliable for confirmation of $P Q$ in waters at concentrations above $20 \mu \mathrm{g} / \mathrm{L}$.

\section{Conclusions}

The three analytical methods presented in this work were successfully validated as bottom-up for PQ analysis in waters. LODs of $10 \mu \mathrm{g} / \mathrm{L}, 0.04 \mu \mathrm{g} / \mathrm{L}$ and $20 \mu \mathrm{g} / \mathrm{L}$ of $\mathrm{PQ}$ were reached for DI-LC-DAD, SPE-LC-DAD and DI-LC-MS methods, respectively. Precision was evaluated for all methods and it was verified that for medium and higher PQ concentrations, the variations in the response are well below $10 \%$ (typically the acceptable error). The DI-LC-DAD method proved to be accurate in the presence of other species or compounds resulting from the contact of the water with deposits and cells, from the PQ commercial formulation (GMX) and from other types of water. Recoveries on average of 77, 99 and $101 \%$ were attained for $0.25,30$ and $80 \mathrm{mg} / \mathrm{L}$ of PQ by DI-LC-DAD method, respectively. It was also shown that for concentrations of $\mathrm{Fe}(\mathrm{II}), \mathrm{H}_{2} \mathrm{O}_{2}$ and $\mathrm{Na}_{2} \mathrm{SO}_{3}$ lower than $6.4 \times 10^{-4}, 5.7 \times 10^{-2}$ and $9.6 \times 10^{-2} \mathrm{M}$, respectively, no effects are observed in the analytical response of the DI-LC-DAD method. It is important to highlight that for the optimum $P Q$ degradation conditions $\left(\left[\mathrm{Fe}^{2+}\right]_{0}=5.0 \times 10^{-4} \mathrm{M},\left[\mathrm{H}_{2} \mathrm{O}_{2}\right]_{0}=1.6 \times 10^{-2}\right.$ $\mathrm{M}$ and $\left.\left[\mathrm{Na}_{2} \mathrm{SO}_{3}\right]=9.6 \times 10^{-2} \mathrm{M}\right)^{[13]}$, there is no influence of Fenton's species on the PQ quantification by this method. Average recoveries of 93 and $97 \%$ were obtained for SPELC-DAD and DI-LC-MS methods, respectively, which account for their good accuracy.

For all methods, the global uncertainty increase with the decrease of PQ concentration. Global uncertainties of 6 to $13 \%$ were obtained for PQ concentrations higher than $5 \mathrm{mg} / \mathrm{L}$ (linearity of 0.1 to $80 \mathrm{mg} / \mathrm{L}$ of $\mathrm{PQ}$ ) by DI-LC-DAD, $5 \mu \mathrm{g} / \mathrm{L}$ (linearity of 0.1 to $50 \mu \mathrm{g} / \mathrm{L}$ of $\mathrm{PQ}$ ) by SPE-LC-DAD and higher than $1 \mathrm{mg} / \mathrm{L}$ (linearity of 0.1 to $10 \mathrm{mg} / \mathrm{L}$ of PQ) by DI-LC-MS. 
All methods proved to be precise, accurate and suitable for the purpose that they were designed.

\section{Acknowledgements}

This work was undertaken as part of the European Research Project SecurEau (http://www.secureau.eu/ - Contract no. 217976), supported by the European commission within the 7th Framework Programme FP7-SEC-2007-1.

Mónica S. F. Santos is grateful to the Portuguese Foundation for Science and Technology (FCT) for her PhD grant (ref. SFRH/BD/61302/2009). The authors are also grateful to FCT for the financial support through the project PTDC/AAC-AMB/101687/2008.

Finally, the authors wish to express their acknowledgement to Gabriela Schaule from the IWW Water Centre (Rheinisch-Westfälisches Institut für Wasserforschung gemeinnützige GmbH - Mülheim an der Ruhr, Germany) for kindly supplying the real deposits. The authors also wish to express their acknowledgements to Dina Martins (from FEUP) for supplying cells of Pseudomonas fluorescens and clay, as well as, the respective composition/characterization of the materials, and to Syngenta Crop Protection, Lda, particularly Eng. Mónica Teixeira, for supplying Gramoxone.

\section{References}

1. Beckie, H.J., Herbicide-resistant weed management: focus on glyphosate. Pest Manag. Sci. 2011, 67, 1037-1048.

2. Eubank, T.W.; Poston, D.H.; Nandula, V.K.; Koger, C.H.; Shaw, D.R.; Reynolds, D.B., Glyphosate-resistant Horseweed (Conyza canadensis) Control Using Glyphosate-, Paraquat-, and Glufosinate-Based Herbicide Programs. Weed Technol. 2008, 22, 16-21. 
3. Lopes, I.C.; de Souza, D.; Machado, S.A.S.; Tanaka, A.A., Voltammetric detection of paraquat pesticide on a phthalocyanine-based pyrolitic graphite electrode. Anal. Bioanal. Chem. 2007, 388, 1907-1914.

4. de Oliveira, U.M.F.; Lichtig, J.; Masini, J.C., Evaluation of a nafion coated glassy carbon electrode for determination of paraquat by differential pulse voltammetry. J. Braz. Chem. Soc. 2004, 15, 735-741.

5. de Souza, D.; Codognoto, L.; Machado, S.A.S.; Avaca, L.A., Electroanalytical determination of the herbicide paraquat in natural water and commercial tea samples with gold electrodes obtained from recordable compact disc. Anal Lett 2005, 38, 331-341. 6. El Mhammedi, M.A.; Bakasse, M.; Chtainia, A., Square-wave voltammetric determination of paraquat at carbon paste electrode modified with hydroxyapatite. Electroanal. 2007, 19, 1727-1733.

7. Pateiro-Moure, M.; Pérez-Novo, C.; Arias-Estévez, M.; Rial-Otero, R.; Simal-Gándara, J., Effect of organic matter and iron oxides on quaternary herbicide sorption-desorption in vineyard-devoted soils. J. Colloid Interface Sci. 2009, 333, 431-438.

8. Fernández, M.; Ibáñez, M.; Picó, Y.; Mañes, J., Spatial and Temporal Trends of Paraquat, Diquat, and Difenzoquat Contamination in Water from Marsh Areas of the Valencian Community (Spain). Arch. Environ. Contam. Toxicol. 1998, 35, 377-384.

9. Amondham, W.; Parkpian, P.; Polprasert, C.; Delaune, R.D.; Jugsujinda, A., Paraquat Adsorption, Degradation, and Remobilization in Tropical Soils of Thailand. J. Environ. Sci. Health, Part B 2006, 41, 485-507.

10. Committee, S.D.W.; Council, N.R., Drinking Water and Health. The National Academies Press: 1977; Vol. 1. 
11. Public health response to biological and chemical weapons-WHO guidance. 2 nd ed.; World Health Organization: Geneva, 2004.

12. SecurEau- Security and decontamination of drinking water distribution systems following a deliberate contamination. http://www.secureau.eu/ (accessed 05-10-2013). 13. Santos, M.S.F.; Alves, A.; Madeira, L.M., Paraquat removal from water by oxidation with Fenton's reagent. Chem. Eng. J. 2011, 175, 279-290.

14. Ellison, S.L.R.; Rosslein, M.; Williams, A., Eurachem/ Citac Guide- Quantification uncertainty in analytical measurement. EURACHEM/ CITAC: UK, 2000; p 7-28.

15. Teixeira, S.; Delerue-Matos, C.; Alves, A.; Santos, L., Fast screening procedure for antibiotics in wastewaters by direct HPLC-DAD analysis. J. Sep. Sci. 2008, 31, 2924-2931.

16. Díaz, A.; Vàzquez, L.s.; Ventura, F.; Galceran, M.T., Estimation of measurement uncertainty for the determination of nonylphenol in water using solid-phase extraction and solid-phase microextraction procedures. Anal. Chim. Acta 2004, 506, 71-80.

17. Ratola, N.; Santos, L.; Herbert, P.; Alves, A., Uncertainty associated to the analysis of organochlorine pesticides in water by solid-phase microextraction/gas chromatographyelectron capture detection-Evaluation using two different approaches. Anal. Chim. Acta 2006, 573-574, 202-208.

18. Oliveira, C.; Santos, M.S.F.; Maldonado-Hódar, F.J.; Schaule, G.; Alves, A.; Madeira, L.M., Use of pipe deposits from water networks as novel catalysts in paraquat peroxidation. Chem. Eng. J. 2012, 210, 339-349.

19. Schlecht, P.C.; O'Connor, P.F., NIOSH Manual of Analytical Methods. 4th ed.; National Institute for Occupational Safety Health: 2003.

20. Miller, J.C.; Miller, J.N., Statistics for analytical chemistry. 2nd ed.; Ellis Horwood: Chichester-England, 1988. 
21. Echeverría, F.; Castaño, J.G.; Arroyave, C.; Peñuela, G.; Ramírez, A.; Morató, J., Characterization of deposits formed in a water distribution system. Rev. Chil. Ing. 2009, $17,275-281$.

22. Santos, M.S.F.; Schaule, G.; Alves, A.; Madeira, L.M., Adsorption of paraquat herbicide on deposits from drinking water networks. Chem. Eng. J. 2013, 229, 324-333.

23. Harris, D.C., Quantitative Chemical Analysis. 6th ed.; W.H. Freeman: New York, 2003.

24. Picó, Y.; Font, G.; Moltó, J.C.; Mañes, J., Solid-phase extraction of quaternary ammonium herbicides. J. Chromatogr. A 2000, 885, 251-271.

25. Martínez Vidal, J.L.; Belmonte Vega, A.; Sánchez López, F.J.; Garrido Frenich, A., Application of internal quality control to the analysis of quaternary ammonium compounds in surface and groundwater from Andalusia (Spain) by liquid chromatography with mass spectrometry. J. Chromatogr. A 2004, 1050, 179-184.

26. Castro, R.; Moyano, E.; Galceran, M.T., Ion-pair liquid chromatography-atmospheric pressure ionization mass spectrometry for the determination of quaternary ammonium herbicides. J. Chromatogr. A 1999, 830, 145-154.

27. Ibáñez, M.; Picó, Y.; Mañes, J., On-line liquid chromatographic trace enrichment and high-performance liquid chromatographic determination of diquat, paraquat and difenzoquat in water. J. Chromatogr. A 1996, 728, 325-331.

28. Ibáñez, M.; Picó, Y.; Mañes, J., Influence of organic matter and surfactants on solidphase extraction of diquat, paraquat and difenzoquat from waters. J. Chromatogr. A $1996,727,245-252$.

29. Carneiro, M.C.; Puignou, L.; Galceran, M.T., Comparison of silica and porous graphitic carbon as solid-phase extraction materials for the analysis of cationic herbicides in water 
by liquid chromatography and capillary electrophoresis. Anal. Chim. Acta 2000, 408, 263269.

30. Rial-Otero, R.; Cancho-Grande, B.; Perez-Lamela, C.; Simal-Gándara, J.; Arias-Estévez, M., Simultaneous determination of the herbicides diquat and paraquat in water. $J$. Chromatogr. Sci. 2006, 44, 539-542.

31. Ibáñez, M.; Picó, Y.; Mañes, J., Improving the solid-phase extraction of 'quat' pesticides from water samples: Removal of interferences. J. Chromatogr. A 1998, 823, 137-146.

32. White, H., Sample preparation strategies for water analysis, Waters Corporation, 2007.

33. Ibánez, M.; Picó, Y.; Manes, J., On-line determination of bipyridylium herbicides in water by HPLC. Chromatographia 1997, 45, 402-407.

34. Grey, L.; Nguyen, B.; Yang, P., Liquid chromatography-electrospray ionization isotope dilution mass spectrometry analysis of paraquat and diquat using conventional and multilayer solid-phase extraction cartridges. J. Chromatogr. A 2002, 958, 25-33.

35. Merino, F.; Rubio, S.; Pérez-Bendito, D., Evaluation and optimization of an on-line admicelle-based extraction-liquid chromatography approach for the analysis of ionic organic compounds. Anal. Chem. 2004, 76, 3878-3886.

36. Núñez, O.; Moyano, E.; Galceran, M.T., Time-of-flight high resolution versus triple quadrupole tandem mass spectrometry for the analysis of quaternary ammonium herbicides in drinking water. Anal. Chim. Acta 2004, 525, 183-190.

37. Munch, J.W.; Bashe, W.J., Method 549.2 - Determination of diquat and paraquat in drinking water by liquid-solid extraction and high performance liquid chromatography 
with ultraviolet detection. U.S. Environmental Protection Agency: Cincinnati, Ohio 45268, 1997.

38. Tucker, B.V.; Pack, D.E.; Ospenson, J.N., Adsorption of bipyridylium herbicides in soil. J. Agric. Food. Chem. 1967, 15, 1005-1008.

39. Perez-Ruiz, T.; Fenoll, J., Spectrofluorimetric determination of paraquat by manual and flow injection methods. Analyst 1998, 123, 1577-1581.

40. Castro, R.; Moyano, E.; Galceran, M.T., Ion-trap versus quadrupole for analysis of quaternary ammonium herbicides by LC-MS. Chromatographia 2001, 53, 273-278.

41. Castro, R.; Moyano, E.; Galceran, M.T., On-line ion-pair solid-phase extraction-liquid chromatography-mass spectrometry for the analysis of quaternary ammonium herbicides. J. Chromatogr. A 2000, 869, 441-449.

42. Castro, R.; Moyano, E.; Galceran, M.T., Determination of quaternary ammonium pesticides by liquid chromatography-electrospray tandem mass spectrometry. J. Chromatogr. A 2001, 914, 111-121. 


\section{Tables}

Table 1. Physical-chemical composition of the deposits ${ }^{[18]}$ and clay and main characteristics.

\begin{tabular}{|c|c|c|c|c|}
\hline & $\mathbf{S 2}$ & S3 & S4 & Clay \\
\hline Deposit classification & Brown & Tubercle & White & ---------------- \\
\hline ICP-OES analysis & Fe: $98 \%$ & Fe: $97 \%$ & Ca: $97 \%$ & $\mathrm{Al}_{2} \mathrm{O}_{3}: 34 \%$ \\
\hline (wt.\% of the main & Ca: $1 \%$ & P: $1 \%$ & Fe: $1 \%$ & $\mathrm{SiO}_{2}: 49 \%$ \\
\hline elements at dry basis) & & Mn: $1 \%$ & Mg: $1 \%$ & \\
\hline $\mathrm{S}_{\mathrm{BET}}, \mathrm{m}^{2} / \mathrm{g}$ & 5 & 36 & 1 & Not determined \\
\hline Surface area $\left(\mathrm{m}^{2} / \mathrm{g}\right)$ & 3.1 & 19.3 & 0.2 & Not determined \\
\hline $\begin{array}{l}\mathrm{pH}_{\mathrm{pzc}}, \\
20^{\circ} \mathrm{C}\end{array}$ & 2.6 & 6.1 & 9.9 & 4.8 \\
\hline $\begin{array}{c}\text { pH in water, } \\
20^{\circ} \mathrm{C}\end{array}$ & 3.3 & 7.2 & 9.0 & 5.3 \\
\hline $\begin{array}{l}\text { Main components } \\
\text { identified by XRD }\end{array}$ & lepidocrocite & goethite & calcite $\left(\mathrm{CaCO}_{3}\right)$ & Not determined \\
\hline $\begin{array}{l}\text { Organic matter } \\
\text { content (wt.\%) }\end{array}$ & 1.0 & 1.0 & 0.2 & 12 \\
\hline
\end{tabular}

Table 2. Precision of the DI-LC-DAD method for analytical standards.

\begin{tabular}{cccc}
\cline { 2 - 4 } & \multicolumn{3}{c}{ PQ concentration (mg/L) } \\
\hline $\mathrm{n}=\mathbf{6}$ & $\mathbf{0 . 2 5}$ & $\mathbf{3 0}$ & $\mathbf{8 0}$ \\
\hline Repeatability (\%) & 15.5 & 0.2 & 0.2 \\
\hline Intermediate Precision (\%) & 21.0 & 2.0 & 1.6
\end{tabular}

Table 3. Recovery assays of the DI-LC-DAD analytical method.

\begin{tabular}{|c|c|c|c|}
\hline \multirow[b]{2}{*}{ Recovery (\%) (n=3) } & \multicolumn{3}{|c|}{ PQ concentration $(\mathrm{mg} / \mathrm{L})$} \\
\hline & 0.25 & 30 & 80 \\
\hline Tap water & $120 \pm 3$ & $99 \pm 1$ & $100 \pm 1$ \\
\hline GMX & $100 \pm 6$ & $101 \pm 1$ & $104 \pm 1$ \\
\hline Deposits & $90 \pm 2$ & $95 \pm 3$ & $94 \pm 4$ \\
\hline
\end{tabular}




\begin{tabular}{ccccc}
\hline & S4 & $109 \pm 4$ & $100 \pm 1$ & $99 \pm 1$ \\
\cline { 2 - 5 } & S3 & $91 \pm 6$ & $102 \pm 1$ & $107 \pm 1$ \\
\cline { 2 - 5 } & S2 & $23 \pm 1$ & $95 \pm 1$ & $105 \pm 1$ \\
\hline Cells & & $6 \pm 2$ & $100 \pm 1$ & $97 \pm 1$ \\
\hline
\end{tabular}

Table 4. Quantitative parameters obtained from PQ analysis in water by SPE-LC-DAD.

\begin{tabular}{ll}
\hline Parameters & SPE-LC-DAD \\
\hline Calibration curve $^{\mathrm{a}}$ & $\mathrm{A}=(94 \pm 1) \times 10^{4} \mathrm{C}(\mu \mathrm{g} / \mathrm{L})+(-2 \pm 3) \times 10^{5}$ \\
Range of linearity $(\mu \mathrm{g} / \mathrm{L})$ & $0.1-50$ \\
Correlation coefficient $(\mathrm{R})$ & 0.9989 \\
$\mathrm{LOD}(\mu \mathrm{g} / \mathrm{L})^{\mathrm{b}}$ & 0.04 \\
$\mathrm{LOQ}(\mu \mathrm{g} / \mathrm{L})^{\mathrm{c}}$ & 0.1
\end{tabular}

${ }^{\mathrm{a}} \mathrm{A}$ is PQ peak area and $\mathrm{C}$ is the concentration in $\mu \mathrm{g} / \mathrm{L} ;{ }^{\mathrm{b}}$ Limit of detection; ${ }^{\mathrm{C}}$ Limit of quantification.

Table 5. Optimal mass spectrometry conditions for PQ determination.

\begin{tabular}{cccccccc}
\hline $\begin{array}{c}\text { Ionization } \\
\text { mode }\end{array}$ & $\begin{array}{c}\text { Capillary } \\
\text { voltage }\end{array}$ & $\begin{array}{c}\text { Needle } \\
\text { voltage }\end{array}$ & $\begin{array}{c}\text { RF } \\
\text { loading }\end{array}$ & $\begin{array}{c}\mathbf{T}_{\text {drying gas }} \\
\left({ }^{\circ} \mathrm{C}\right)\end{array}$ & $\begin{array}{c}\mathbf{P}_{\text {drying gas }} \\
\text { (psi) }\end{array}$ & $\begin{array}{c}\mathbf{P}_{\text {nebulization gas }} \\
\text { (psi) }\end{array}$ & $\begin{array}{c}\text { Excitation } \\
\text { amplitude }\end{array}$ \\
\hline positive & 87 & 3839 & 77 & 400 & 20 & 50 & \\
\hline
\end{tabular}

Table 6. Quantitative parameters obtained from PQ analysis in water by DI-LC-MS.

\begin{tabular}{ll}
\hline Parameters & LC-MS \\
\hline Calibration curve $^{\mathrm{a}}$ & $\mathrm{A}=(185 \pm 2) \times 10^{5} \mathrm{C}(\mathrm{mg} / \mathrm{L})+(-6 \pm 9) \times 10^{5}$ \\
Range of linearity $(\mathrm{mg} / \mathrm{L})$ & $0.1-10$ \\
Correlation coefficient $(\mathrm{R})$ & 0.9991 \\
$\mathrm{LOD}(\mathrm{mg} / \mathrm{L})^{\mathrm{b}}$ & 0.02 \\
$\left.\mathrm{LOQ}^{\mathrm{m}} \mathrm{mg} / \mathrm{L}\right)^{\mathrm{c}}$ & 0.06
\end{tabular}

${ }^{a} \mathrm{~A}$ is $\mathrm{PQ}$ peak area and $\mathrm{C}$ is the concentration in $\mathrm{mg} / \mathrm{L} ;{ }^{\mathrm{b}}$ Limit of detection; ${ }^{\mathrm{c}}$ Limit of quantification.

Table 7. Analytical method precision for analytical standards.

\begin{tabular}{cccc}
\cline { 2 - 4 } & \multicolumn{3}{c}{ PQ concentration (mg/L) } \\
\cline { 2 - 4 } & $\mathbf{0 . 2}$ & $\mathbf{5}$ & $\mathbf{1 0}$ \\
\hline Repeatability (\%) (n=6) & 5.3 & 4.0 & 3.8 \\
\hline Intermediate Precision (\%) & 12.9 & 5.9 & 6.4 \\
$(\mathbf{n = 3 )}$ & & & \\
\hline
\end{tabular}




\section{Figure Captions}

Figure 1. Calibration curve for PQ quantification in water by DI-LC-DAD.

Figure 2. (a) Relative weight of each individual source of uncertainty (bottom-up approach/EURACHEM) (b) Global uncertainty of the analytical methodology for PQ quantification in waters by DI-LC-DAD.

Figure 3. Influence of the presence of $\mathrm{FeSO}_{4}$ in paraquat quantification by DI-LC-DAD.

Figure 4. Influence of the presence of $\mathrm{Na}_{2} \mathrm{SO}_{3}$ and $\mathrm{H}_{2} \mathrm{O}_{2}$ in $\mathrm{PQ}$ quantification by DI-LCDAD.

Figure 5. Calibration curve for $\mathrm{PQ}$ quantification in water and in different concentrations of $\mathrm{Na}_{2} \mathrm{SO}_{3}$ by DI-LC-DAD.

Figure 6. Optimization of solid phase extraction methodology.

Figure 7. (a) Relative weight of each individual source of uncertainty (bottom-up approach/EURACHEM) (b) Global uncertainty of the analytical methodology for PQ quantification in waters by SPE-LC-DAD.

Figure 8. Calibration curve for PQ quantification in water by DI-LC-MS.

Figure 9. (a) Relative weight of each individual source of uncertainty (bottom-up approach/EURACHEM) (b) Global uncertainty of the analytical methodology for PQ quantification in waters by DI-LC-MS. 
Title: Different approaches for paraquat quantification in waters

Authors: Mónica S. F. Santos, Luis M. Madeira and Arminda Alves

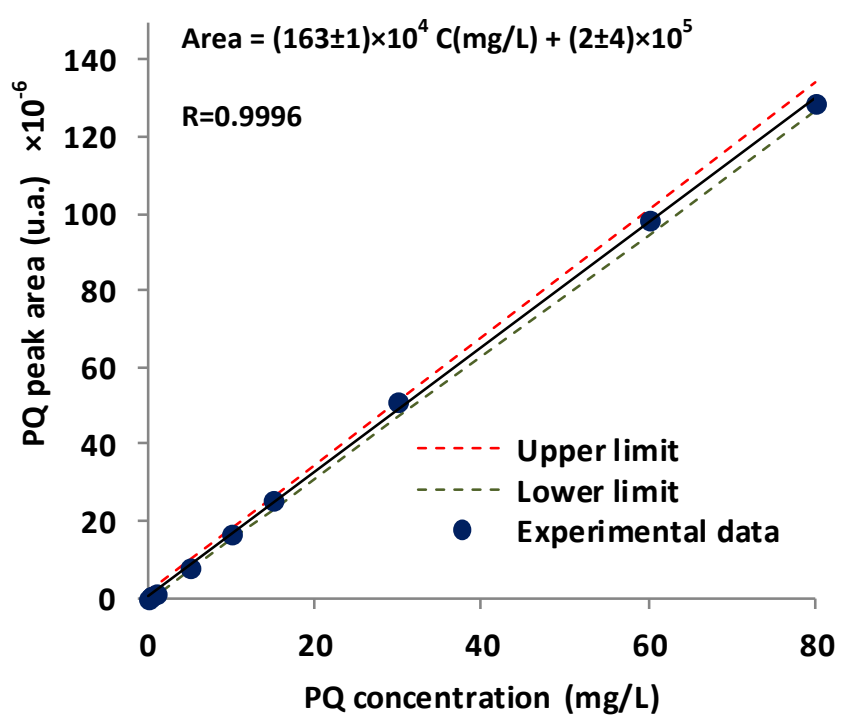

Figure 1. Calibration curve for PQ quantification in water by DI-LC-DAD. 
Title: Different approaches for paraquat quantification in waters

Authors: Mónica S. F. Santos, Luis M. Madeira and Arminda Alves
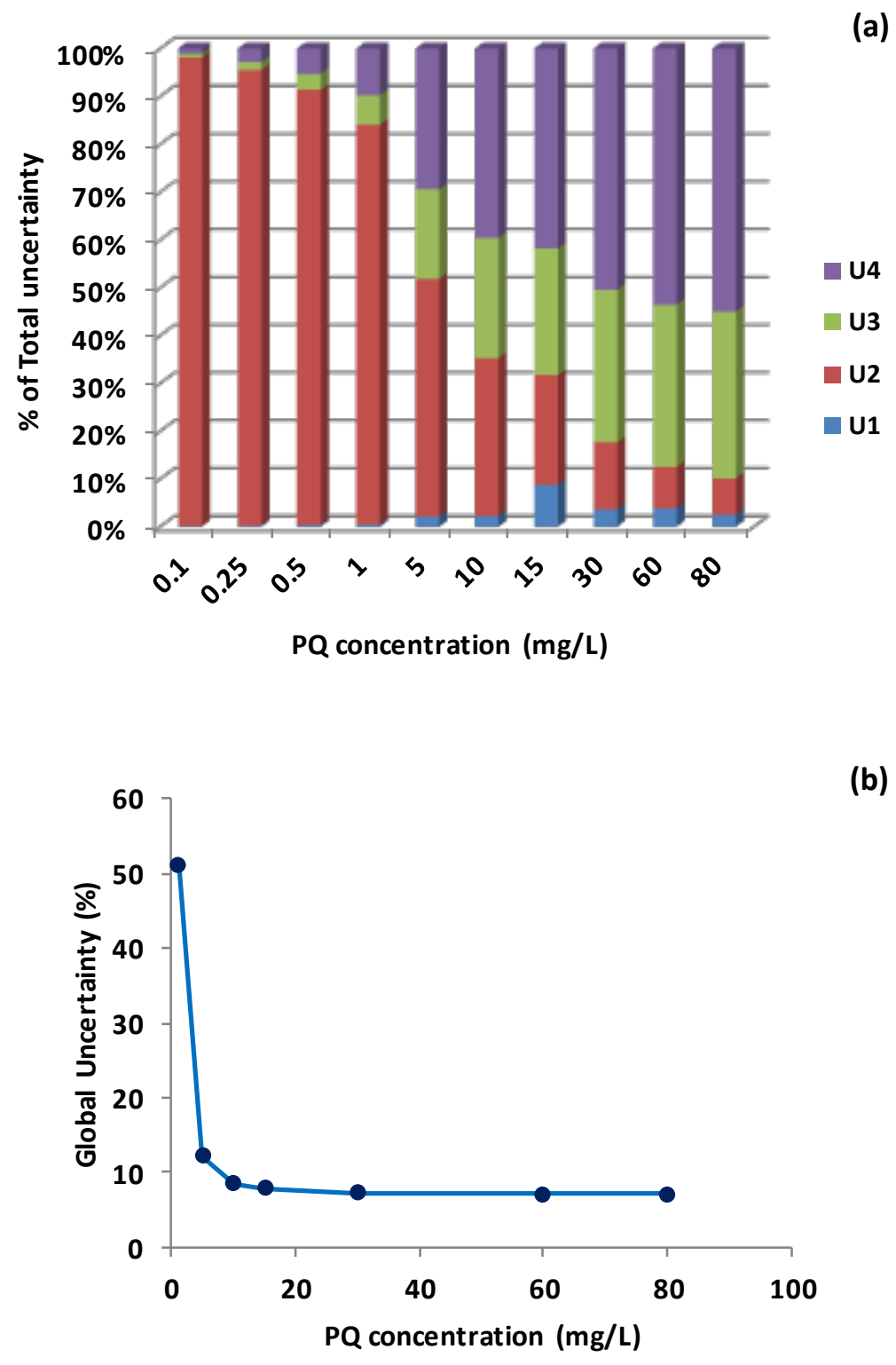

(b)

Figure 2. (a) Relative weight of each individual source of uncertainty (bottom-up approach/EURACHEM) (b) Global uncertainty of the analytical methodology for PQ quantification in waters by DI-LC-DAD. 
Title: Different approaches for paraquat quantification in waters

Authors: Mónica S. F. Santos, Luis M. Madeira and Arminda Alves

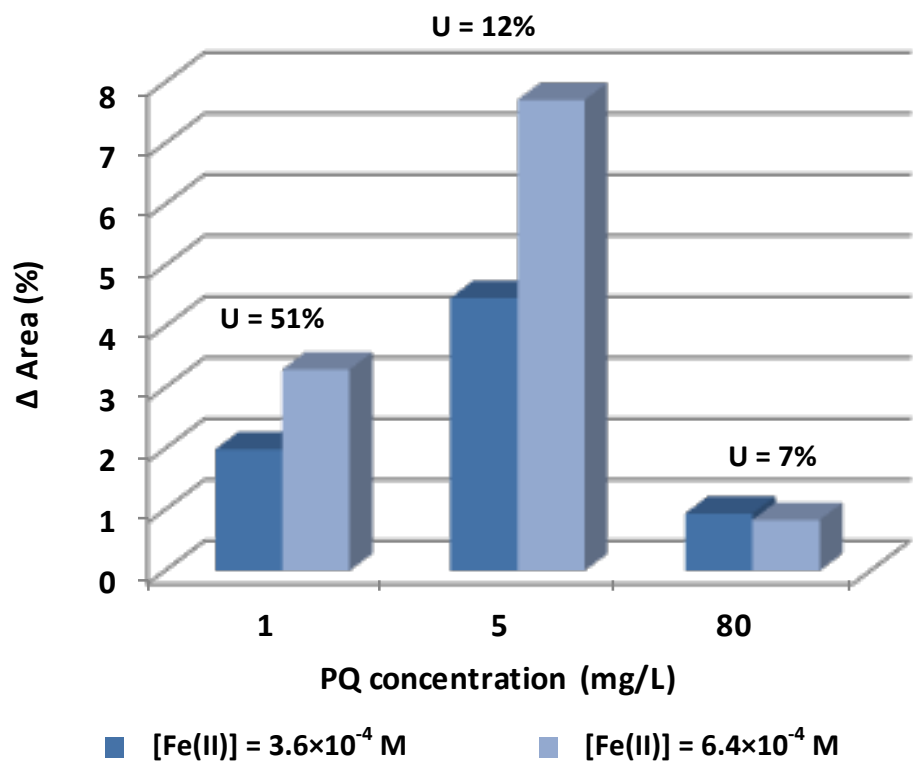

Figure 3. Influence of the presence of $\mathrm{FeSO}_{4}$ in paraquat quantification by DI-LC-DAD. 
Title: Different approaches for paraquat quantification in waters

Authors: Mónica S. F. Santos, Luis M. Madeira and Arminda Alves

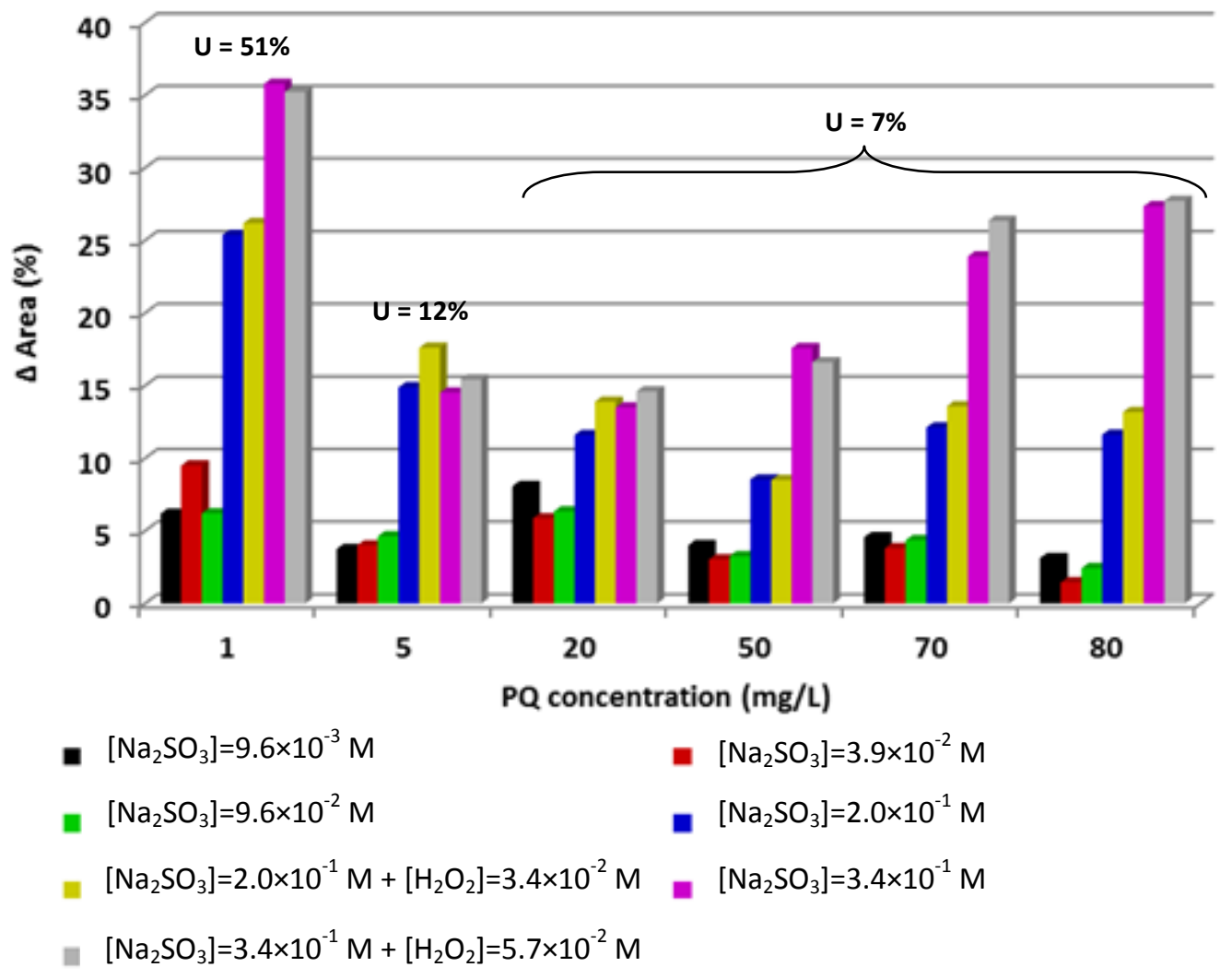

Figure 4. Influence of the presence of $\mathrm{Na}_{2} \mathrm{SO}_{3}$ and $\mathrm{H}_{2} \mathrm{O}_{2}$ in PQ quantification by DI-LCDAD. 
Title: Different approaches for paraquat quantification in waters

Authors: Mónica S. F. Santos, Luis M. Madeira and Arminda Alves

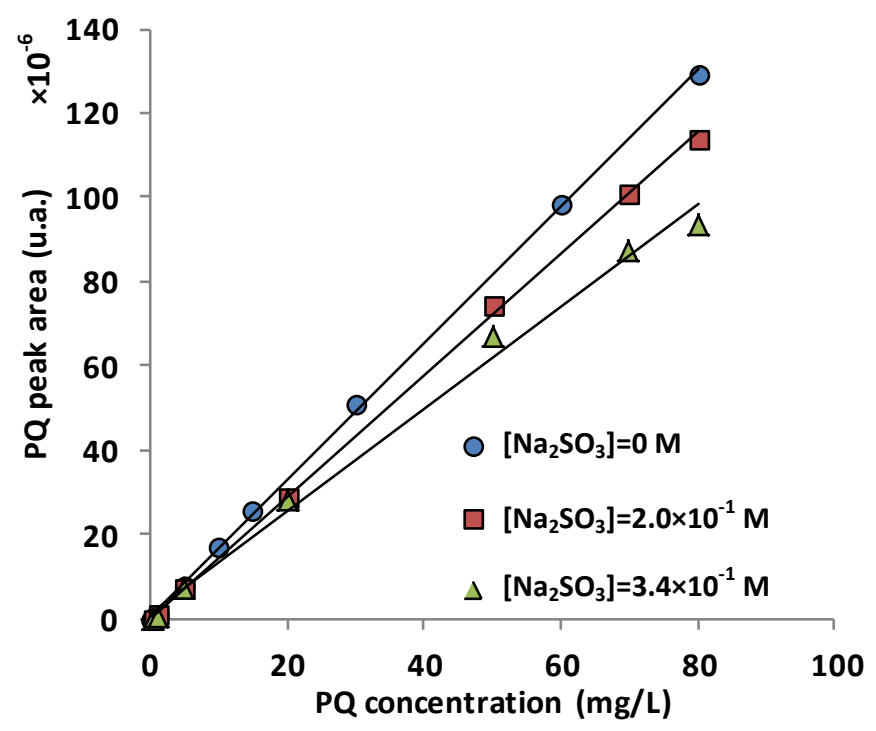

Figure 5. Calibration curve for $P Q$ quantification in water and in different concentrations of $\mathrm{Na}_{2} \mathrm{SO}_{3}$ by DI-LC-DAD. 
Title: Different approaches for paraquat quantification in waters

Authors: Mónica S. F. Santos, Luis M. Madeira and Arminda Alves

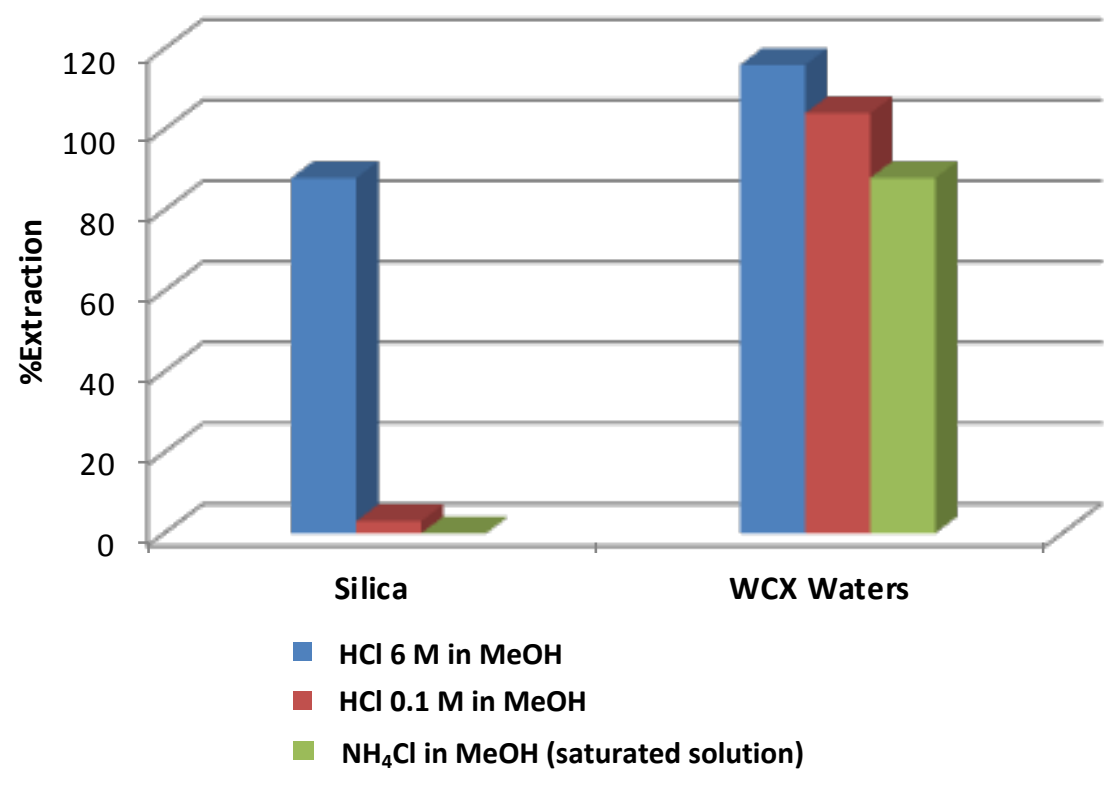

Figure 6. Optimization of solid phase extraction methodology. 
Title: Different approaches for paraquat quantification in waters

Authors: Mónica S. F. Santos, Luis M. Madeira and Arminda Alves
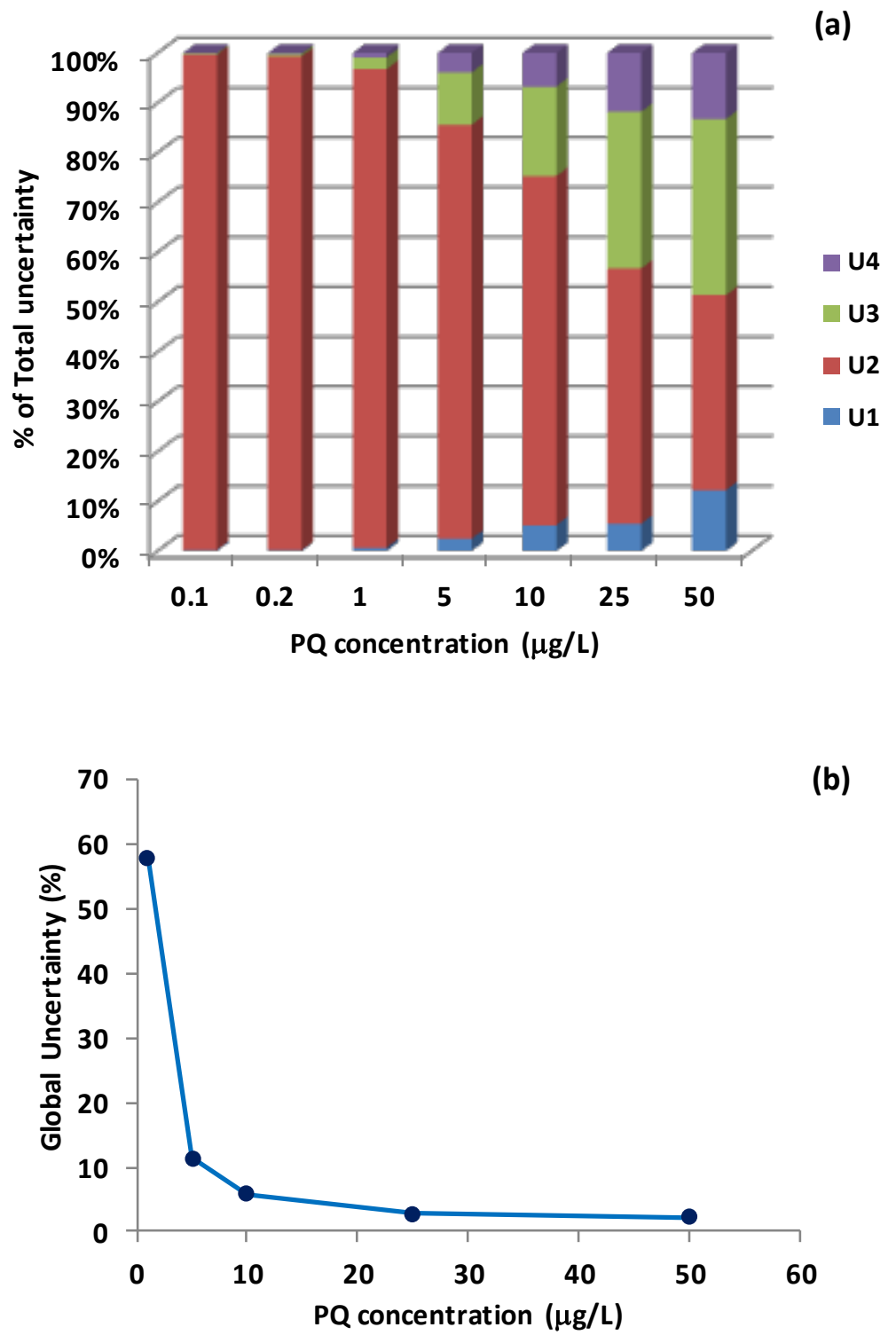

(b)

Figure 7. (a) Relative weight of each individual source of uncertainty (bottom-up approach/EURACHEM) (b) Global uncertainty of the analytical methodology for PQ quantification in waters by SPE-LC-DAD. 
Title: Different approaches for paraquat quantification in waters

Authors: Mónica S. F. Santos, Luis M. Madeira and Arminda Alves

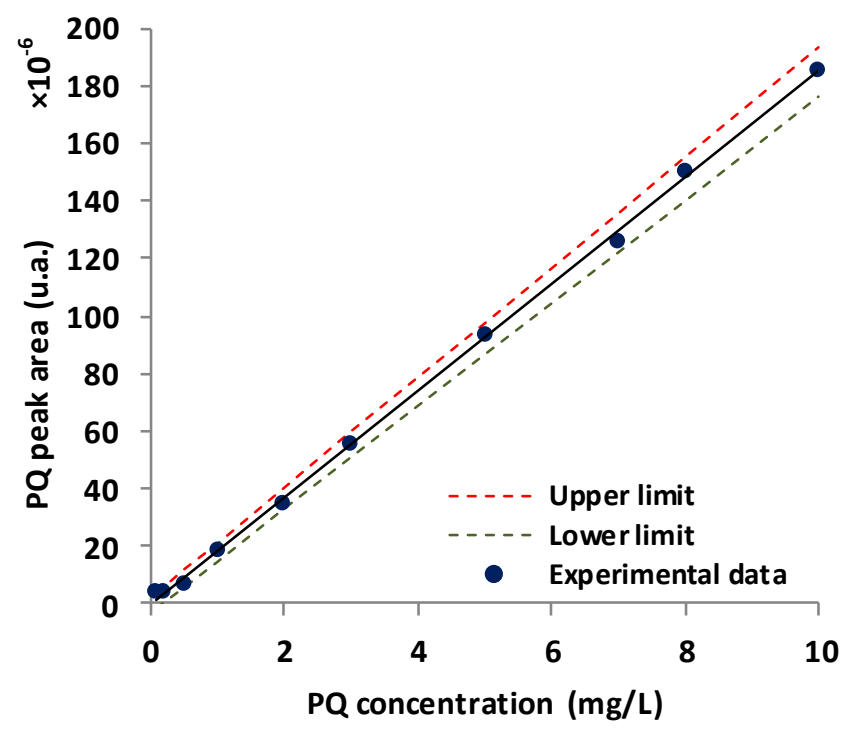

Figure 8. Calibration curve for PQ quantification in water by DI-LC-MS. 
Title: Different approaches for paraquat quantification in waters

Authors: Mónica S. F. Santos, Luis M. Madeira and Arminda Alves
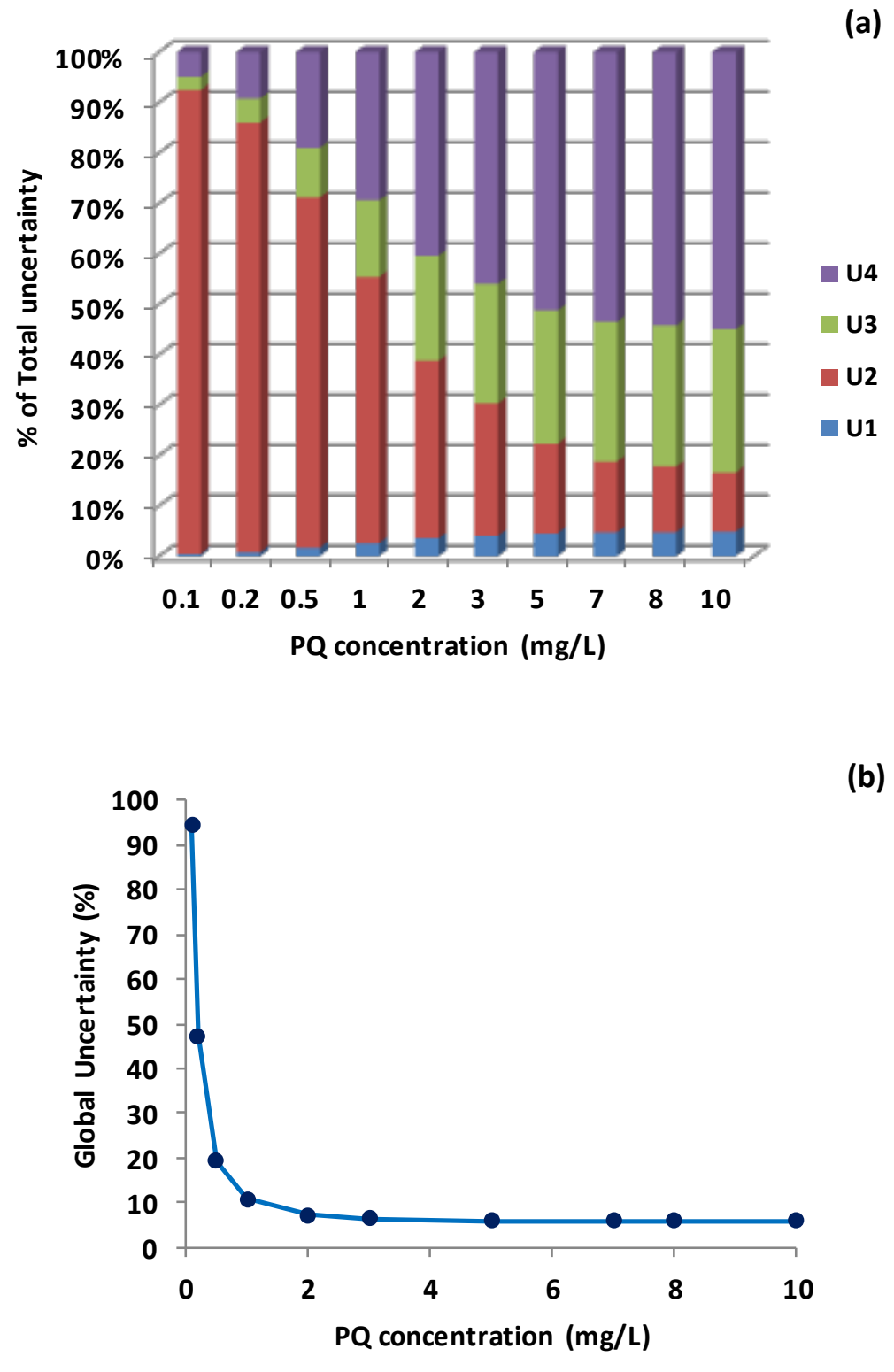

(b)

Figure 9. (a) Relative weight of each individual source of uncertainty (bottom-up approach/EURACHEM) (b) Global uncertainty of the analytical methodology for PQ quantification in waters by DI-LC-MS. 